\title{
ENDOCRINOPATHIES AFTER PEDIATRIC HSCT: SCREENING RECOMMENDATIONS AND MANAGEMENT
}

\author{
Adriana Aparecida Siviero-Miachon ${ }^{1 *}$, Paulo Alonso Garcia Alves-Junior ${ }^{2 *}$, Angela Maria Spinola- \\ Castro $^{3}$, Maria Alice Neves Bordallo ${ }^{4}$
}

1 Professor and Pediatric Endocrinologist, Federal University of Sao Paulo - UNIFESP/EPM, Grupo de Apoio à Criança e ao Adolescente com Câncer - GRAACC, and Associação para Crianças e Adolescentes com Câncer - TUCCA/Santa Marcelina, E-mail: aasmiachon@unifesp.br-2Pediatric Endocrinologist, Cancer National Institute - Ministry of Heath (INCA), E-mail:pagaj@live. com - 3Professor and Pediatric Endocrinologist, UNIFESP/EPM, GRAACC, and TUCCA/Santa Marcelina

760 Borges Lagoa Str., ZIP 04038-001, Sao Paulo, Brazil, Phone/Fax: +55 11 5579-9409, E-mail: endocrino@angelaspinola. com.br-4Professor and Endocrinologist, Estadual University of Rio de Janeiro-UERJ, and INCA, E-mail: malicebordallo@ terra.com.br - *Both authors contributed equally to this work

\begin{abstract}
Endocrine disorders after pediatric hematopoietic stem cell transplantation are the consequence of the interaction between the underlying disease, host characteristics, and treatment, including exposure to pre- and peri-transplantation agents (chemotherapy and radiotherapy). Moreover, post-transplantation factors comprising graft versus host disease and its treatment, especially glucocorticoids, also contribute to hormone deficiencies or endocrine diseases. Endocrinological changes may be divided into six major groups: 1) Growth disorders; 2) Thyroid diseases; 3) Gonadal dysfunction; 4) Adrenal failure; 5) Bone mineral density deficit; 6) Metabolic syndrome. The goal of this paper is to define screening recommendations for diverse endocrine diseases and management approaches, addressing the following important issues: define populations at risk for a particular endocrine disturbance, recommendations during follow-up, and management strategies for treatment focusing on controversial remarks.

KEYWORDS: bone marrow transplantation; graft vs host disease; glucocorticoids; growth disorders; adrenal insufficiency; thyroid gland/radiation effects; gonads/drug effects; adiposity; atherosclerosis; bone and bones/metabolism.
\end{abstract}

\section{INTRODUCTION}

Endocrinological changes post-hematopoietic stem cell transplantation (HSCT) may be interpreted as a result of the synergistic interaction between the underlying disease, host characteristics, exposure to pre- and peri-HSCT factors (chemotherapeutic agents, conditioning regimen and radiotherapy, RT), and post-HSCT factors, including graft versus host disease (GVHD). Endocrinopathies are among the most frequent late effects associated with pediatric $\mathrm{HSCT}$, affecting nearly $60 \%$ of subjects receiving HSCT before 10 years of age, and with the onset between 0.8 to 9.5 years after HSCT. ${ }^{[1-3]}$

Endocrine abnormalities changes in patients after HSCT may be divided into six major groups: 1) Growth disorders; 2) Thyroid diseases; 3) Gonadal dysfunction; 4) Adrenal failure; 5) Bone mineral density deficit; 6) Metabolic syndrome. The goal of this paper is to define populations at risk for a particular endocrine disturbance, propose recommendations during follow-up, and management strategies for treatment focusing on controversial remarks. ${ }^{[3,4]}$

\section{METHODS}

These recommendations were carried out by a group of experts in the field of late effects and endocrinological complications after HSCT, and are not based on evidence derived from randomized controlled trials (scarce or nonexistent), but are supported by retrospective studies and international guidelines that have identified late endocrine complications, and their associated risk-factors. When those studies are 
not available, strategies are based on knowledge derived from non-transplant patients. The recommendations should not be interpreted as mandatory for all recipients; good medical practice and judgment dictate that certain recommendations may not be applicable in individual patients. ${ }^{[2,3,5]}$

\section{GROWTH DISORDERS}

Growth is usually one of the most disturbed events among children treated for cancer, and it may be also adversely affected by HSCT, especially depending on the disease pre-HSCT and other factors, particularly cranial RT in doses $\geq 18$ Gy at younger ages, and less frequently due to chemotherapy. Total body irradiation (TBI) at a single fraction dose of $10 \mathrm{~Gy}$ or a fractionated dose of $12 \mathrm{~Gy}$ may lead to growth hormone $(\mathrm{GH})$ deficiency. Those patients exposed to a dose of cranial $\mathrm{RT} \geq 30 \mathrm{~Gy}$ are at a higher risk for $\mathrm{GH}$ deficiency. Growth may be additionally affected by severe illness, malnutrition, GVHD, prolonged glucocorticoids, other hormonal deficiencies, including hypothyroidism, and hypogonadism. 2,6,7

HSCT recipients treated with recombinant human $\mathrm{GH}$ (rhGH) may still grow poorly after TBI due to end organ resistance. Early pubertal onset (more common after cranial RT) may accelerate growth and initially mask GH insufficiency. 5,7 Concerns have been raised among original cancer recurrence and second neoplasms in pediatric patients treated with rhGH. Studies have not supported recurrence while data among second neoplasms showed an initial 3-fold increase, however with decline over time, with no risk associated with subsequent brain tumors. ${ }^{5,7-10}$

\section{GROWTH DISORDERS RECOMMENDATIONS}

- HSCT recipients who had not attained final height should be evaluated every 6 months regarding height, weight, body mass index (BMI), growth velocity and pubertal stage (Tanner).

- Patients subjected to cranial RT $\geq 30$ Gy should have pituitary hormones routinely assessed, including GH axis.

- Survivors growing poorly should have thyroid function evaluated.

- Consider risks versus benefits of rhGH replacement therapy.

\section{THYROID DISEASES}

Thyroid dysfunctions are recognized as one of the major endocrine complications after HSCT and include subclinical hypothyroidism, overt hypothyroidism, hyperthyroidism (rare), autoimmune thyroiditis, and thyroid nodules (thyroid cancer). ${ }^{[3,5,11]}$ Thyroid gland is particularly sensitive to the effects of RT especially at a very young age, in females, cumulative doses of RT $\geq 20 \mathrm{~Gy}$, with prolonged interval since exposure, and GHVD. Notably, thyroid cancer risk decreases at RT doses > $30 \mathrm{~Gy}$, in which there is both ablation and fibrosis of thyroid tissue. Single-dose ablative TBI is the major risk factor associated with a $50 \%$ of incidence of overt hypothyroidism, whereas fractionated TBI is associated with an incidence of $15 \%$ at a median 4 years after HSCT. Nonetheless, isolated chemotherapy (busulfan and cyclophosphamide) may lead to hypothyroidism, frequently transient, in $11 \%$ of patients. Treatments given prior to HSCT are also important factors, such as neck and/or cranial RT.2,12 The transfer of autoimmunity from graft donors may cause autoimmune thyroid disease, comprising hypothyroidism or hyperthyroidism. ${ }^{[3,4]}$

Subclinical hypothyroidism is the most frequent type of thyroid dysfunction, occurs in $7-15 \%$ of patients in the first year after HSCT, in which thyroid-stimulating hormone (TSH) is between ${ }^{[5-10]} \mathrm{mIU} / \mathrm{L}$ and a normal free thyroxine (FT4). There are no recommendations in patients exposed to RT so treatment should be individualized. ${ }^{[13-16]}$ Overt hypothyroidism is another scenario, with TSH $>10$ mIU/L, low-normal FT4 levels, and clinical symptoms. In this case, sodium levothyroxine is strongly indicated. ${ }^{[15]}$ 
Thyroid nodules are usually present approximately 10 years after exposure to RT and are very likely to be malignant, being considered a second neoplasm. $[13,14,16]$

As a consequence of the high prevalence of thyroid disease in the general population, patients should have their thyroid assessed before undergoing HSCT. It is not suggested to evaluate thyroid function immediately after HSCT, because dysfunctions among this period are usually due to sick euthyroid syndrome, an entity that does not need treatment. ${ }^{17}$ Thyroid antibodies help differentiate RT-induced hypothyroidism from autoimmune causes. Cervical ultrasound should be performed in those with altered thyroid palpation. Thyroid nodules should be carefully evaluated and, depending on the ultrasound imaging, a fine-needle aspiration biopsy should be performed. The management of thyroid cancer secondary to neck RT follows the same guidelines as in the primary disease. ${ }^{[2,3,5,13,14,16]}$

\section{THYROID DISEASES RECOMMENDATIONS}

- Survivors with any neck RT should have TSH and FT4 performed one year after HSCT, and yearly thereafter, unless clinical symptoms (e.g., poor growth velocity).

- Palpation of thyroid gland should be performed in every clinical examination.

- The role of cervical ultrasound in screening thyroid nodules is still controversial.

\section{GONADAL DYSFUNCTION}

Gonadal dysfunction is highly prevalent in HSCT recipients, generally higher in women $(99 \%$ in females, and $92 \%$ in males). The conditioning regimens for HSCT, comprising chemotherapy alone (alkylating and platinum-based agents) or associated with TBI may lead to a high prevalence of gonadal damage, which manifests as delayed puberty, post-pubertal gonadal insufficiency, or impaired fertility. Gonadotropins comprising luteinizing hormone (LH) and follicle stimulating hormone (FSH) may also be compromised by cranial RT $\geq 30 \mathrm{~Gy}$ administered prior to TCTH. ${ }^{[2-5]}$

\section{MALES}

In male patients, chemotherapy may damage spermatogenesis (Sertoli cells), particularly at cumulative doses of cyclophosphamide $\geq 7.5 \mathrm{gm} / \mathrm{m}^{2}$ leading to oligospermia and/or azoospermia. Leydig cells (testosterone producing) appear to be more resistant to the toxic effects of drugs than Sertoli cells, and manifest dysfunction at doses $\geq 20 \mathrm{gm} / \mathrm{m} 2$ of cyclophosphamide. Concerning RT, germ cells are also more sensitive, with permanent azoospermia likely after ${ }^{[6-}$ ${ }^{10]} \mathrm{Gy}$, while testosterone insufficiency occurs only at doses $\geq 20 \mathrm{~Gy}$. There is a synergistic effect between cytostatic drugs and RT leading to azoospermia, but testosterone secretion generally unimpaired so that most patients complete puberty at an expected time. ${ }^{[2-5,18-20]}$ GVHD has also been responsible for transitory changes in the germinal epithelium leading to azoospermia in patients not exposed to RT. ${ }^{[20,21]}$ Sperm cryopreservation should be indicated prior to treatment if possible. Sex hormone replacement therapy follows similar guidelines as in other non-cancer populations. ${ }^{[2-5,20]}$

\section{FEMALES}

In contrast to males, the ovary has no difference between gonadotoxic effect on hormonal production or fertility (oocyte production), being both sections equally damaged (premature ovarian failure). Older age ( $>10$ years), and pubertal status at the time of exposure increase the risk of ovarian dysfunction, being associated with lower doses of RT among pubertal (5-10 Gy) versus prepubertal girls (10-15 Gy). TBI leads to definitive gonadal failure in almost all patients who were already pubertal at the time of HSCT. $[5,18,22]$ The association of cyclophosphamide and busulfan in HSCT conditioning regimens may 
also lead to delayed pubertal development and/ or permanent damage to ovarian function, even though dose thresholds are less well-established. ${ }^{[5,6,23]}$ Patients who recovered ovarian function years after HSCT may later lead to early menopause. ${ }^{[24]}$ Cryopreservation of ovarian cortical tissue before treatment may be a source of oocytes, and a pos- sibility for reproductive purposes. ${ }^{[25]}$ Sex hormone replacement therapy follows similar guidelines as in other non-cancer populations. Nonetheless, if there is an increased thrombotic risk, transdermal estrogen should be preferred. Replacement therapy does not increase the risk of breast cancer secondary to $\mathrm{RT}$, and/or the recurrence of primary disease. ${ }^{[2,3,5]}$

\section{GONADAL DYSFUNCTION RECOMMENDATIONS}

- Periodic monitoring of pubertal development, sexual and reproductive function after high doses of alkylating, TBI, and/or cranial RT.

- In at-risk males (exposed to alkylating doses and/or TBI): periodically assess testicular volume that may be a sign of impairment of germinal epithelium. Monitor total testosterone, LH, and FSH after age 13-14. Consider semen analysis if desired.

- In at-risk females: periodic follow-up with estradiol, LH, and FSH at age 12-13.

- Discuss with patient and/or guardians the possibility of infertility.

- Encourage patients who want to preserve their fertility to seek for specialized services.

\section{ADRENAL FAILURE}

Therapy with glucocorticoids in high doses or during a prolonged period may suppress the pituitary-adrenal axis and cortisol secretion. Cranial RT $\geq 30$ Gy may rarely compromise adrenocorticotropic hormone (ACTH) secretion. Chronic fatigue, weakness, anorexia, nausea, vomiting, weight loss, postural hypotension, hyponatremia, hypokalemia and hypoglycemia occasionally are signs and symptoms of primary or secondary adrenal failure. Function usually recovers gradually once exogenous glucocorticoid therapy is discontinued, although retrieval time is quite variable, from days to months, and ACTH suppression may persist one year after therapy withdrawal. ${ }^{[2,4]}$
The adrenal gland is radioresistant. Even though referred incidence of adrenal failure in HSCT recipients is usually low, certainly many cases remain undiagnosed and the recommended main approach is prevention. Patients with prolonged exposure to glucocorticoids (e.g., in GVHD) should have adrenal axis evaluated after exposure ends, particularly if suspicious symptoms of hypoadrenalism are present. Consider the possibility of adrenal insufficiency and "stress doses" in patients receiving long-term glucocorticoids who develop acute illness ${ }^{[2,4]}$

\section{ADRENAL FAILURE RECOMMENDATIONS}

- In patients with chronic GHVD after prolonged glucocorticoid, therapy withdrawal should be gradual.

- Patients withdrawing from prolonged glucocorticoids should have "stress doses" during acute illness.

\section{BONE MINERAL DENSITY DEFICIT}

Another potential endocrine complication of HSCT is bone loss, characterized by low bone mineral density (BMD), presented in $24-48 \%$ of patients, usually ${ }^{[3-12]}$ months after HSCT. Bone fragility is multifactorial and depends on a complex interaction between pre, peri-and post-transplant treatments. Preferen- tial differentiation of mesenchymal stem cells towards adipogenesis, rather than osteogenesis is a suggested additional mechanism for BMD deficit. ${ }^{[3-5,56-29]}$ All survivors of HSCT are at risk for bone loss, possibly due to the following risk factors: advanced and younger age at HSCT (due to reduced bone ac- 
quisition during puberty), Caucasian ethnicity, female sex, low weight/ BMI, TBI, cranial RT, untreated endocrinopathies (hypogonadism, GH deficiency or hyperthyroidism), granulocyte colony-stimulating factor (G-CSF) treatment, renal dysfunction, calcium and vitamin D deficiency, GHVD, and its treatment with prolonged glucocorticoids (particularly dexamethasone), methotrexate, and calcineurin inhibitors (cyclosporine, and tacrolimus)..$^{[4,27,30}$ An initial evaluation of serum calcium, phosphorous, parathyroid hormone, renal function, and $25 \mathrm{OH}$ vitamin $\mathrm{D}$ is usually recommended. Bone turnover markers may be assessed, but their value in clinical practice is limited, especially in growing children and adolescents.27 Dual-energy X-ray absorptiometry (DXA) is used for evaluation of BMD. In adults, a T-score $<-2.5$ indicates osteoporosis and between -1.0 and -2.5 means osteopenia. ${ }^{[31]}$ In children, the whole body (without head) and lumbar spine (L1-L4) are the sites for assessing bone mass. A Z-score $<-2.0$ indicates a low BMD for age, and preferably should be adjusted for height. ${ }^{[32]}$ A T-score $<-2.5$ in adults or a Z-score $<$ -2.0 in children should be considered for treatment with bisphosphonates. ${ }^{[5,27]}$

A healthy lifestyle with an adequate dietary calcium intake, physical activity, and sun exposure (if possible), while avoiding smoking and alcohol or carbonated beverages should be encouraged. If $25 \mathrm{OH}$ vitamin D levels are under $30 \mathrm{ng} / \mathrm{mL}$, supplementation is indicated. ${ }^{[33]}$

\section{BONE MINERAL DENSITY DEFICIT RECOMMENDATIONS}

- All survivors are encouraged to have a healthy lifestyle with adequate calcium intake, regular physical activity, and sun exposure.

- All survivors should undergo a BMD evaluation through DXA one year post-transplant.

Longitudinal data indicate patients at risk, and repeated evaluations depend on previous results.

- A Z-score <-2.0 in children with multiple fractures should be considered for bisphosphonates therapy, even though the optimal schedule is not determined so far.

\section{METABOLIC SYNDROME}

The components of the metabolic syndrome (MetS), known as the risk factors for cardiovascular disease (CVD) are, as follows: abdominal obesity, insulin resistance (IR), diabetes mellitus (DM), dyslipidemia, and hypertension. ${ }^{[1,34}$

All survivors of pediatric HSCT experience components of the MetS at a higher rate than in the general population, possibly due to host factors, such as obesity and family history, in addition to cranial RT, TBI and transplant complications (i.e., GVHD, liver disease, and hormonal deficits). It is well known that prolonged treatment with immunosuppressive drugs, such as glucocorticoids and calcineurin inhibitors (tacrolimus) affect beta cell function, but survivors who were off immunosuppressive treatment may also experience metabolic derangements.
Conditioning with TBI damages pancreatic islet cell, leading to impaired glucose metabolism, associated with changes in body composition known as the sarcopenic obesity, characterized by increased fatness and decreased lean mass. ${ }^{[3,34-39]}$ Other factors may contribute to persistent metabolic derangements after HSCT such as: immune system dysfunction, inflammatory mechanisms, leptin resistance and changes in microbiome composition. ${ }^{[3,40]}$

Accelerated atherosclerosis and premature CVD are one of the most important causes of morbidity and mortality among long-term survivors after HSCT, and are related either to the allo-reaction or to the early appearance of the components of the MetS. The most frequent cardiovascular events are coronary heart disease and cerebrovascular accidents, with an incidence of $7.5 \%$ in 15 years, and $22 \%$ over 25 years. ${ }^{[1,2,41,42]}$ 
It is recommended to initiate surveillance of asymptomatic individuals one year after HSCT, screening recipients treated with abdominal $\mathrm{RT}$, including $\mathrm{TBI}$, by measuring body weight, and metabolic profile. $[1,2,3,5]$ Non-pharmacologic lifestyle modifications remain the first step in the management of metabolic derangements in HSCT survivors. Insulin-sensitizers (metformin) are not recommended to IR so far. There is also no specific guidance in the management of dyslipidemia in HSCT survivors treated during childhood. ${ }^{[3,39]}$

\section{METABOLIC SYNDROME RECOMMENDATIONS}

- Routine clinical assessment of BMI, waist-to-height ratio, and blood pressure for all HSCT recipients one year and yearly after, especially if RT exposure.

- Survivors treated with any abdominal RT should be screened with fasting glucose (and glycated hemoglobin, $\mathrm{HbA} 1 \mathrm{c})$, insulin, homeostatic model assessment (HOMA1-IR), and lipids every 2 years. In those with lab alterations, follow-up must be individualized.

- Counseling on a healthy lifestyle with diet and physical exercise.

- Appropriate drug therapy of CVD risk factors should be performed based on specific published guidelines.

\section{CONCLUSIONS}

Survivors of pediatric HSCT are a heterogeneous population as they are exposed to different underlying diseases, and various pre-transplant treatment options. The transplantation itself is quite diverse, and comprises multiple conditioning regimens, and important post-transplant adverse effects. Thus, they are vulnerable to late-onset endocrine effects, which may exacerbate adverse general health outcomes. The better understanding of the epidemiology and risk factors of the endocrine dysfunctions, the importance of longitudinal follow-up for early diagnosis and management, and the development of strategies in order to minimize worsened general health outcomes may possibly increase the quality of life in this particular group of patients.

\section{ACKNOWLEDGEMENTS}

The authors thank all their HSCT patients and families.

\section{REFERENCES}

1.Rovó A, Tichelli A; Late Effects Working Party of the European Group for Blood and Marrow Transplantation. Cardiovascular complications in long-term survivors after allogeneic hematopoietic stem cell transplantation. Semin Hematol. v. 49, p. 25-34, 2012.

2.Majhail NS, Rizzo JD, Lee SJ, Aljurf M, Atsuta $Y$, Bonfim C; Center for International Blood and
Marrow Transplant Research; American Society for Blood and Marrow Transplantation; European Group for Blood and Marrow Transplantation; Asia-Pacific Blood and Marrow Transplantation Group; Bone Marrow Transplant Society of Australia and New Zealand; East Mediterranean Blood and Marrow Transplantation Group; Sociedade Brasileira de Transplante de Medula Ossea. Recommended Screening And Preventive Practices For Long-Term Survivors After Hematopoietic Cell Transplantation. Hematol Oncol Stem Cell Ther. v. 5, p. 1-30, 2012.

3.Paetow U, Bader P, Chemaitilly W. A Systematic Approach to the Endocrine Care of Survivors of Pediatric Hematopoietic Stem Cell Transplantation. Cancer Metastasis Rev. v. 39, p. 69-78, 2020.

4.Akirov A, Sawka AM, Ben-Barouch S, Lipton J, Ezzat S. ENDOCRINE COMPLICATIONS IN PATIENTS WITH GVHD. Endocr Pract. v. 25, p. 485-90, 2019.

5.Chow EJ, Anderson L, Baker KS, Bhatia S, Guilcher GM, Huang JT, et al. Late Effects Surveillance Recommendations Among Survivors of Childhood Hematopoietic Cell Transplantation: A Children's Oncology Group Report. Biol Blood Marrow Transplant. v. 22, p. 782-95, 2016.

6.Sanders JE. Endocrine complications of highdose therapy with stem cell transplantation. $\mathrm{Pe}$ diatr Transplant. v.8, p. 39-50, 2004. 
7.Crowne $E$, Gleeson $H$, Benghiat $H$, Sanghera $P$, Toogood A. Effect of cancer treatment on hypothalamic-pituitary function. Lancet Diabetes Endocrinol. v. 3, p. 568-76, 2015.

8.Raman S, Grimberg A, Waguespack SG, Miller BS, Sklar CA, Meacham LR, et al. Risk of Neoplasia in Pediatric Patients Receiving Growth Hormone Therapy--A Report From the Pediatric Endocrine Society Drug and Therapeutics Committee. J Clin Endocrinol Metab. v. 100, p. 2192-2203, 2015.

9.Ergun-Longmire $B$, Mertens AC, Mitby $\mathrm{P}$, Qin J, Heller G, Shi W, et al. Growth hormone treatment and risk of second neoplasms in the childhood cancer survivor. J Clin Endocrinol Metab. v. 91, p. 3494-98, 2006.

10.Patterson BC, Chen Y, Sklar CA, Neglia J, Yasui Y, Mertens A, et al. Growth hormone exposure as a risk factor for the development of subsequent neoplasms of the central nervous system: a report from the childhood cancer survivor study. $J$ Clin Endocrinol Metab. v. 99, p. 2030-7, 2014.

11.Cima LN, Martin SC, Lambrescu IM, Stejereanu L, Zaharia C, Colita A, et al. Long-term thyroid disorders in pediatric survivors of hematopoietic stem cell transplantation after chemotherapy-only conditioning. J Pediatr Endocrinol Metab. v. 31, p. 869-78, 2018.

12.Sanders JE, Hoffmeister PA, Woolfrey AE, Carpenter PA, Storer BE, Storb RF, et al. Thyroid function following hematopoietic cell transplantation in children: 30 years' experience. Blood. v. 113, p. 306-8, 2009.

13.Rose SR, Lustig RH, Pituksheewanont $\mathrm{P}$, Broome DC, Burghen GA, Li H, et al. Diagnosis of hidden central hypothyroidism in survivors of childhood cancer. J Clin Endocrinol Metab. v. 84, p. 4472-9, 1999.

14.Chemaitilly W, Sklar CA. Endocrine Complications of Hematopoietic Stem Cell Transplantation. Endocrinol Metab Clin N Am. v.36, p. 983-98, 2007.

15.Lazarus J, Brown RS, Daumerie C, Hubalewska-Dydejczyk A, Negro R, Vaidya B. 2014 European Thyroid Association Guidelines for the Management of Subclinical Hypothyroidism in Pregnancy and in Children. Eur Thyroid J. v. 3, p. 76-94, 2014.

16.Shalitin S, Pertman L, Yackobovitch-Gavan M, Yaniv I, Lebenthal Y, Phillip M, et al. Endocrine and Metabolic Disturbances in Survivors of Hematopoietic Stem Cell Transplantation in Childhood and Adolescence. Horm Res Paediatr. v. 89, p. 108-21, 2018.

17.Matsumoto $M$, Ishiguro $H$, Tomita $Y$, Inoue $H$, Yasuda $Y$, Shimizu T, et al. Changes in thyroid function after bone marrow transplant in young patients. Pediatr Int. . v. 46, p. 291-5, 2004.

18.Borgmann-Staudt A, Rendtorff R, Reinmuth S, Hohmann C, Keil T, Schuster FR, et al. Fertility after allogeneic hematopoietic stem cell transplantation in childhood and adolescence. Bone Marrow Transplant. v. 47, p. 271-6, 2012.

19.Couto-Silva AC, Trivin C, Thibaud E, Esperou H, Michon J, Brauner R. Factors affecting gonadal function after bone marrow transplantation during childhood. Bone Marrow Transplant. v. 28, p. 67-75, 2001.

20.Bordallo MA, Guimarães MM, Pessoa CH, Carriço MK, Dimetz T, Gazolla HM, et al. Decreased serum inhibin $\mathrm{B} / \mathrm{FSH}$ ratio as a marker of Sertoli cell function in male survivors after chemotherapy in childhood and adolescence. $J$ Pediatr Endocrinol Metab. v. 17, p. 879-81, 2004.

21.Rovó A, Aljurf M, Chiodi S, Spinelli S, Salooja N, Sucak G; Late Effects Working Party of the EBMT. Ongoing graft-versus-host disease is a risk factor for azoospermia after allogeneic hematopoietic stem cell transplantation: a survey of the Late Effects Working Party of the European Group for Blood and Marrow Transplantation. Haematologica. v. 98, p. 339-45, 2013.

22.Sanders JE, Pritchard S, Mahoney P, Amos D, Buckner CD, Witherspoon RP, et al. Grow and development following marrow transplantation for leukemia. Blood. v. 68, p. 1129-35, 1986.

23.De Sanctis V, Galimberti M, Lucarelli G, Polchi P, Ruggiero L, Vullo C. Gonadal function after allogenic bone marrow transplantation for thalassaemia. Arch Dis Child. v. 66, p. 517-20, 1991.

24.Sklar CA, Mertens AC, Mitby P, Whitton J, Stovall $M$, Kasper $C$, et al. Premature menopause in survivors of childhood cancer: a report from the childhood cancer survivor study. J Natl Cancer Inst. v. 98, p. 890-6, 2006.

25.Donnez J, Silber S, Andersen CY, Demeestere I, Piver $P$, Meirow $D$, et al. Children born after autotransplantation of cryopreserved ovarian tissue. 
A review of 13 live births. Ann Med. v. 4, p.437$50,2011$.

26.Salooja N, Greinix H, Ruutu T, van der Werf S, van Biezen A, Lawitschka A, et al. Investigation and Management of Bone Mineral Density Following Hematopoietic Cell Transplantation: A Survey of Current Practice by the Transplant Complications Working Party of the European Society for Blood and Marrow Transplantation. Biol Blood Marrow Transplant. v. 51083-8791, p. 30387-9, 2020.

27.Kendler DL, Body JJ, Brandi ML, Broady R, Cannata-Andia J, Cannata-Ortiz MJ, et. al. Bone management in hematologic stem cell transplant recipients. Osteoporosis International. v. 29, p. 2597-610, 2018.

28.Gubrianska D, Machaczka M, Hassan M, Hägglund $\mathrm{H}$, Ljungman $\mathrm{P}$, Palmér $\mathrm{M}$. Bone and hormonal status 10 years post-allogeneic bone marrow transplantation. Clin Transplant. v. 33, p. 13742, 2019.

29.Siviero-Miachon AA, Lee MLM, Guerra-Junior G, Spinola-Castro AM. Are Survivors of Childhood Acute Lymphoblastic Leukemia at Increased Risk for Low Bone Mass? J Leuk. v. 2, p. 150, 2014.

30.Armas LAG, Recker RR. Pathophysiology of osteoporosis new mechanistic insights. Endocrinol Metab Clin N Am. v. 41, p. 475-86, 2012.

31.Albergaria BH, Chalem M, Clark P, Messina OD, Pereira RMR, Vidal LF. Consensus statement: osteoporosis prevention and treatment in Latin America-current structure and future directions. Arch Osteoporos. v. 13, p. 90, 2018.

32.Bachrach LK, Gordon CM; SECTION ON ENDOCRINOLOGY. Bone Densitometry in Children and Adolescents. Pediatrics. v. 138, p. 20162398, 2016.

33.Institute of Medicine (US) Committee to Review Dietary Reference Intakes for Vitamin D and Calcium. Dietary Reference Intakes for Calcium and Vitamin D. Ross AC, Taylor CL, Yaktine AL, Del Valle HB, editors. Washington (DC): National Academies Press (US); 2011.

34.Siviero-Miachon AA, Spinola-Castro AM, Guerra-Junior $\mathrm{G}$. Detection of metabolic syndrome features among childhood cancer survivors: a target to prevent disease. Vasc Health Risk Manag. v. 4, p. 825-36, 2008.

35.Taskinen M, Saarinen-Pihkala UM, Hovi L, Lipsanen-Nyman M. Impaired glucose tolerance and dyslipidaemia as late effects after bone-marrow transplantation in childhood. Lancet. v. 356, p. 993-7, 2000.

36.Chemaitilly W, Boulad F, Oeffinger KC, Sklar $C A$. Disorders of glucose homeostasis in young adults treated with total body irradiation during childhood: A pilot study. Bone Marrow Transplant. v. 44, p. 339-43, 2009.

37.Wei C, Thyagiarajan MS, Hunt LP, Shield JP, Stevens $M C$, Crowne EC. Reduced insulin sensitivity in childhood survivors of haematopoietic stem cell transplantation is associated with lipodystropic and sarcopenic phenotypes. Pediatr Blood Cancer. v. 62, p. 1992-9, 2015.

38.Paris C, Yates L, Lama P, Zepeda AJ, Gutierrez D, Palma J. Evaluation of metabolic syndrome after hematopoietic stem cell transplantation in children and adolescents. Pediatr Blood Cancer. v. 59, p. 306-10, 2012.

39.Armenian SH, Chemaitilly W, Chen M, Chow EJ, Duncan CN, Jones LW, et al. National Institutes of Health hematopoietic cell transplantation late effects Initiative:The Cardiovascular Disease and Associated Risk Factors Working Group Report. Biol Blood Marrow Transplant. v. 23, p. 20110, 2017.

40.Turcotte LM, Yingst A, Verneris MR. Metabolic syndrome after hematopoietic cell transplantation: At the intersection of treatment toxicity and immune dysfunction. Biol Blood Marrow Transplant. v. 22. p. 1159-66, 2016.

41.Tichelli A, Passweg J, Wójcik D, Rovó A, Harousseau JL, Masszi T, et al. Late cardiovascular events after allogeneic hematopoietic stem cell transplantation: a retrospective multicenter study of the Late Effects Working Party of the European Group for Blood and Marrow Transplantation. Haematologica. v. 93, p. 1203-10, 2008.

42.Armenian $\mathrm{SH}$, Sun $\mathrm{CL}$, Mills $\mathrm{G}$, Teh JB, Francisco L, Durand JB, et al. Predictors of late cardiovascular complications in survivors of hematopoietic cell transplantation. Biol Blood Marrow Transplant. v. 16, p. 1138-44, 2010. 